\title{
Value creation disclosure: the international integrated reporting framework revisited in the light of stakeholder theory
}

\author{
Renata Paola Dameri and Pier Maria Ferrando \\ Department of Economics and Business Studies, University of Genoa, Genoa, Italy
}

Department of Economics and Business Studies, University of Genoa, Genoa, Italy

\begin{abstract}
Purpose - The paper aims to propose an integrated reporting (IR) framework rooted in Freeman's stakeholder theory (ST). The proposed framework modifies the international integrated reporting framework (IIRF) and aims to overcome criticisms related to its focus on investors and the abandonment of sustainability.

Design/methodology/approach - The paper develops a modified IIRF based on an in-depth analysis of the IR and ST literature. The framework was then applied to a non-profit health-care organisation to verify its theoretical assumptions.

Findings - The modified IIRF was conceived as a ready-to-use tool. By applying it to a business case, it was validated with respect to whether and how it could help achieve better and more stakeholder-oriented reporting. The findings enabled us to validate the use of the tool not only for reporting but also for the selfassessment of organisations with respect to embedding ST.

Research limitations/implications - The modified IIRF was implemented only in one case, and further implementations are needed to comprehensively identify its strengths and weaknesses, both in forprofit and non-profit organisations.

Practical implications - The revised IIRF represents an updated tool for reporting and disclosing the value created by an organisation for itself and for its stakeholders including the external entities affected by the impacts engendered by the organisation. In this way, the IIRF can give visibility to all value created and the value creation process, including sustainability matters. This allows integrated thinking processes to be incorporated accordingly, supporting better management.

Originality/value - This paper suggests three adjustments to improve the IIRF's ability to incorporate ST as a theoretical foundation. The adjusted IIRF is a ready to-use-tool specifically highlighting what value or values an organisation delivers (its outcomes), for whom (its stakeholders) and how (its specific business processes) within a business model effectively connecting them. From this point of view, it fits the rising stream about the evolution of the sustainability reporting fostered jointly by the international integrated reporting council and sustainability accounting standard board, and by the European Union.
\end{abstract}

Keywords Stakeholder theory, Integrated reporting, Non-financial disclosure, Value creation, Purpose firm

Paper type Research paper

(C) Renata Paola Dameri and Pier Maria Ferrando. Published by Emerald Publishing Limited. This article is published under the Creative Commons Attribution (CC BY 4.0) licence. Anyone may reproduce, distribute, translate and create derivative works of this article (for both commercial and non-commercial purposes), subject to full attribution to the original publication and authors. The full terms of this licence may be seen at http://creativecommons.org/licences/by/4.0/legalcode

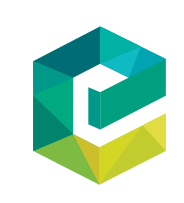

Received 27 November 2020 Revised 31 March 2021 19 June 2021 
MEDAR

30,3

\section{Introduction}

Since it was published in 2013, the international integrated reporting framework (IIRF) has gained consensus worldwide as a tool for the non-financial disclosure of corporations, public bodies and non-profit organisations (Samy, 2015; De Villiers et al., 2017; Guthrie et al., 2017; Adams and Simnett, 2011). The aim of the IIRF is to report on an organisation's ability to create value. It is based on the concept of integrated thinking (Adams, 2015), which is the active consideration by an organisation of the relationships between its various operating and functional units and the capitals that the organisation uses or affects (Coulson et al., 2015).

However, the IIRF is not without its critics (Flower, 2015; Biondi et al., 2020), with some claiming that it is primarily for the benefit of providers of financial capital rather than organisational stakeholders (IIRC, 2013, p. 2). Even though stakeholder relationships are a basic principle of integrated reporting (IR) (Rensburg and Botha, 2014; García-Sánchez and Noguera-Gámez, 2017), the IIRF mainly focusses on the value that an organisation creates for itself, whilst the value it creates for others plays a subordinate role (IIRC, p. 10). Sukhari and De Villiers (2019) found that stakeholder relationships are one of the more neglected aspects of IR, despite it being one of the pillars of the IIRF.

The aim of this paper is to overcome the limitations of traditional IR and its focus on investors by suggesting a modified IR framework rooted in creating value for stakeholders and using Freeman's stakeholder theory (ST) as the theoretical lens.

Since the mid-1980s, value creation for stakeholders has increasingly emerged as a key aspect of strategic management (Harrison et al., 2020). ST posits that to be successful, organisations must serve the interests and expectations of all their stakeholders rather than focussing on a particular group (Freeman, 1984; Friedman and Miles, 2006; Phillips and Freeman, 2010). ST is contrary to the notion that the ultimate aim of the corporation is to maximise shareholder returns (Jensen, 2001; Barney, 2018).

ST is an ante litteram version of the concept of integrated thinking upon which the IIRF is based because it affirms that all stakeholder interests should be managed as a whole (Harrison et al., 2020). However, the IIRF is not based on ST and focuses on the value an organisation creates for itself rather than on the explicit causal links between business practices, key stakeholders, value creation and increases or decreases in six capitals.

However, the IIRF focusses on the value an organisation creates for itself and stakeholders are not the primary recipients of value creation. As a consequence, this setting blurs the explicit casual links between business practices, key stakeholders, value creation and increases or decreases in the six capitals, limiting the integrated thinking enabled by the IIRF (De Villiers et al., 2014; Dumay et al., 2016). These relationships have not been sufficiently highlighted (De Villiers et al., 2017; Zambon et al., 2019) and deserve to be examined more comprehensively.

To incorporate ST into IR, a modified framework was developed based on an in-depth analysis of the IR and ST literature and an empirical study to verify the theoretical assumptions. The modified framework emerged from adjustments made to the IIRF to improve the disclosure of an organisation's ability to create value for all of its stakeholders in an integrated way (Dameri and Ferrando, 2020). The modified IIRF includes some original details and provides operational implications that are worth highlighting. Firstly, the traditional IIRF defines value creation as merely an increase in any of the six capitals, whilst the modified IIRF includes the fulfilment of stakeholder expectations in value creation. Secondly, the modified IIRF is more suitable for stakeholder- and purpose-oriented organisations because it enables the reporting of stakeholder satisfaction and firm purpose, which are increasingly required (Millstein et al., 2019). Finally, the modified IIRF is a ready- 
to-use tool, supporting IR preparers to write stakeholder-oriented reports, filling the gap in the research on the relationships between ST and IR and the implementation of these relationships (Vitolla et al., 2019a, 2019b).

The modified IIRF was validated by empirically investigating its use in a non-profit health-care organisation. The findings enabled to the refinement of the modified IIRF, which was found to be more effective in disclosing and reporting value creation for stakeholders. Moreover, the research outcomes can be extended to for-profit corporations.

The remainder of the paper is structured as follows. Section 2 describes the methodology for

Value creation disclosure the structured literature review and case study. Section 3 presents the literature and defines the theoretical lens supporting the research. Section 4 introduces adjustments to the IIRF, Section 5 explains its implementation in a case study and Section 6 discusses the findings. Section 7 outlines the research limitations and makes recommendations for future research.

\section{Methodology}

\subsection{Literature review on stakeholder theory and integrated reporting}

A systematic literature review (Fink, 2005) was conducted to identify the basic features of ST, its evolution over the past 30 years and whether and how it intersects with IR. We adopted a systematic, explicit, comprehensive and reproducible method, including both bibliographic and thematic analyses, to support the robustness of our results (Rowley and Slack, 2004).

Vitolla et al. (2019a) conducted a systematic review of the literature on ST and IR to classify the research according to normative and descriptive perspectives and identify an agenda that will be able to guide future studies. We refer to this paper, but we have used a different literature review protocol: Vitolla et al. root their protocol in their previous knowledge on integrated reporting to define the space of research and identify the research keywords before the survey (Vitolla et al., p. 519). We have adopted the conventional content analysis as suggested by Hsieh and Shannon (2005), therefore, we did not define the keywords before the survey: we simply defined the space of research as ST; then, we derived codes from the reading of the papers, counting and comparing the text's content.

The following steps were followed for the systematic literature review:

(1) Identify the scope and aims of the literature review.

(2) Choose the parameters for paper selection, including keywords, sources and period of publication.

(3) Analyse the selected papers to extract knowledge.

(4) Classify the findings and report the results.

1. Firstly, the aims of the literature review were identified. These aims were to investigate the meaning and evolution of ST over the past 30 years and understand whether and how ST intersects with the IIRF to enhance its ability to report on and disclose the value an organisation creates for its stakeholders.

2. These aims determined the choice of parameters for paper selection. The Scopus database was used to search for papers because it includes highly ranked journals in business, management and accounting. Accordingly, two different searches were carried out: ST meanings and evolution and the link between ST and IR. To search for articles on ST, the search term "stakeholder theory" was entered into the "title" field, returning 325 papers. Only papers from the business, management and accounting disciplines were selected to ensure they aligned with the aims of our review. Moreover, only journal articles and book chapters were included to examine the most valuable works. This reduced the sample size to 
MEDAR

30,3

\section{2}

192 papers. The second search on the link between ST and IR was conducted by entering the phrase "integrated reporting AND stakeholder theory" into the "title" field, which returned only one paper. The search was then repeated with the same search terms entered into the "title", "abstract" and "keywords" fields. This yielded 24 papers from 2013 onwards, with 20 of these papers published in the past 2 years.

3. To analyse the selected papers, we adopted conventional content analysis (Hsieh and Shannon, 2005) aimed at identifying recurring themes with respect to ST. Our approach was rooted in inductive coding (Chandra and Shang, 2019), a data analysis process whereby the researcher repeatedly reads, compares and interprets raw textual data to develop concepts or themes. We used inductive coding without a predefined code frame because this was less prone to bias and more flexible. The aim was to identify codes linked to the research aims:

Text analysis was applied to the title, keywords and abstracts of the 192 papers on ST and to the title, keywords, abstract and text of the 24 papers on ST and IR. The process began with firstorder coding of key sentences explaining the aim of each paper. Then, the assigned labels were shared and reviewed by members of the research team, who combined the codes into themes. To summarise the findings, all 192 papers on ST were assigned to a category depending on the coding for the main topic of each paper. These findings are summarised in Table 1.

Table 1 highlights the research fields in which ST has been linked to key topics in business management. The first group of papers $(n=53)$ pertained to managerial practices, correlating with Freeman's (1984) original formulation of ST and including strategic management $(n=28)$, corporate governance $(n=11)$ and performance $(n=14)$. The second group of papers $(n=22)$ pertained to the relationship between ST and the nature and aims of the firm $(n=18)$ and non-profit organisations $(n=4)$. The third group of papers $(n=68)$ investigated ST through an ethical lens, with papers pertaining to ethical issues $(n=30)$, corporate social responsibility $(n=21)$ and, from 2003 , the environmental impact of business activities $(n=17)$. The fourth group of papers $(n=39)$ pertained to the evolution of ST with respect to relations and communications with stakeholders, including their classification and involvement $(n=27)$ and disclosure activities $(n=12)$. This last group of papers was concentrated from 2005 onwards. A small group of papers $(n=10)$ pertained to public policies, a topic more likely to be addressed in journals outside of the business, management and accounting discipline.

The results of this systematic literature review were used to build the theoretical framework (Section 3).

\begin{tabular}{clcccr}
\hline & & \multicolumn{3}{c}{ Year } \\
No. & Theme & Pre 2000 & $2000-2010$ & $2010-2020$ & Total \\
\hline 1 & Corporate social responsibility & 3 & 5 & 13 & 21 \\
2 & Disclosure & 1 & 5 & 6 & 12 \\
3 & Performance & 2 & 2 & 10 & 14 \\
4 & Ethics & 5 & 14 & 11 & 30 \\
5 & Non-profit & 1 & 3 & - & 4 \\
6 & Stakeholders & 1 & 11 & 15 & 27 \\
7 & Corporate governance & 1 & 5 & 5 & 11 \\
8 & Nature and aims of the firm & 3 & 9 & 6 & 18 \\
9 & Environmental sustainability & - & 7 & 10 & 17 \\
10 & Strategic management & - & 10 & 18 & 28 \\
11 & Public policies & - & - & 10 & 10 \\
Total & & 17 & 71 & 104 & 192 \\
\hline
\end{tabular}

Table 1.

Result of the literature review on ST 
With respect to the analysis of the literature on ST and IR, the 24 papers were read in their entirety. The common aspect linking them was their reference to ST as the theoretical lens on which to base research (Vitolla et al., 2019a, 2019b). Some authors referred to the need for more (or better) information on stakeholder pressures (Farneti et al., 2019), whilst others used ST to justify the commitment of companies and IR preparers to improve disclosure (Dameri and Ferrando, 2020). Finally, several studies used ST to justify the ethical behaviours of companies in improving the disclosure of non-financial information regarding sustainability, environmental preservation or the common good (Frias-Aceituno et al., 2013). None of the 24 papers used ST to modify the IIRF or the disclosure content of IR.

Given that these topics were intertwined and often occurred concurrently in papers, it is only possible to report the topics linking IR to ST rather than build a taxonomy (similar to that in Table 1).

\subsection{Action research to validate the theoretical findings}

A case study (Yin, 1994) was undertaken to test the theoretical framework that emerged from the literature review and validate the theoretical constructs (Eisenhardt, 1989). The case study involved an in-depth investigation of an organisation that wished to use IR to disclose the value created for its stakeholders. The case study enabled the collection, analysis and interpretation of primary data on the topic (Yin, 1994).

Given that the authors participated in the preparation and drafting of the first edition of the integrated report, the case study was based on action research (Kemmis et al., 2013), which involved concurrently conducting research and taking action, then reflecting on the consequences of actions to understand, develop and improve managerial practices (Burns, 2007). Indeed, being personally involved in the preparation of the integrated report, the authors of this paper had the opportunity to operationalise their theoretical framework. In this case, action research was confirmatory (Janssens et al., 1995) because it made it possible to test and validate the theoretical hypotheses emerging from the results of the systematic literature review.

The case study was the Gigi Ghirotti Association (GGA), a medium-sized, non-profit health-care organisation established in 1984 in Genoa, Italy. GGA provides palliative care and assistance to patients with terminal cancer, acquired immune deficiency syndrome and amyotrophic lateral sclerosis (motor neuron disease), as well as their families. GGA owns two premises in the city and provides both in-home and hospice-based services. It is a wellknown and highly regarded organisation that plays a pivotal role in the local area, satisfying health needs and expectations that would otherwise remain unfulfiled. With respect to its relations with its stakeholders and the local community, GGA faces challenges in making its outcomes known and promoting its image. For this reason, the association has been issuing a social report since 2009. At the end of 2017, unsatisfied with the quality and effectiveness of its disclosure to stakeholders, GGA requested support from the Department of Economics and Business Studies at Genoa University in updating and improving its longstanding social report. Thus, cooperation was born, providing the opportunity to test the adjusted IIRF.

To conduct the empirical research, a project team was formed, including four academic researchers (the authors of this paper and two postgraduate students) and three GGA managers: the chief financial officer (CFO), the chief operating officer (COO) and a member of the GGA supervisory board. The work was organised as a series of learning and action meetings (Carr and Kemmis, 1986) to diagnose problems, plan actions, implement solutions and reflect on outcomes. 
MEDAR

30,3

\section{4}

Data were collected from July 2018 to April 2019 from the following:

- Meeting minutes: Over the course of six meetings, GGA representatives discussed solutions and obtained feedback about the gradual implementation of the adjusted IIRF. Following each GGA meeting, the researchers attended academic meetings, seeking to learn from the actions taken and improve the solutions at each cycle.

- Semi-structured interviews: These involved the CFO, COO and member of the supervisory board of GGA. The questions pertained to the association's aims and mission, internal processes, disclosure documents, perceived importance of different stakeholders and awareness about critical resources.

- Proprietary reports and documents.

Interviews were transcribed and coded in conjunction with the proprietary documents, particularly those on financial and social reporting.

The project was completed at the beginning of 2019 and GGA's Integrated Report 2018 (www.gigighirotti.it/wp-content/uploads/2019/05/integrated-report.pdf) was released in the spring of 2019. GGA is committed to issuing a regular integrated report in the long term.

\section{Background and theoretical framework}

3.1 Evolution of stakeholder theory: embedding stakeholder theory into the purpose view of the firm

Although it has been rooted in numerous previous works (Dodd, 1932; Stewart et al., 1963; Pitelis and Wahl, 1998), ST was officially born in 1984, when R. E. Freeman published his book Strategic Management: A Stakeholder Approach. As the title of this book makes clear, ST was conceived as a managerial practice to improve the success of corporations by pursuing value creation for all stakeholders rather than only shareholders using an integrated approach (Smith, 2003; Phillips et al., 2003).

ST was originally defined by Freeman (1984) as a managerial practice to help companies operate in complex environments in which rapid changes and environmental problems were acquiring increasing importance. Management can no longer be based on simple inputoutput mechanisms but must be based on a "hub and spoke" model in which firms affect and are affected by multiple factors (Freeman, 1984; Donaldson and Preston, 1995). A corporation's success depends on the quality of these relationships.

Freeman proposed an innovative vision of the firm in which strategies are aimed at balancing the needs of all stakeholders. This requires a redefinition of the nature and role of the firm that opposes the notion of shareholder primacy (Jensen, 2001) and the firm as an instrument to accomplish shareholders' goals (Asher et al., 2005; Balmer et al., 2007). Consequently, the so-called normative ST (Donaldson and Preston, 1995) was used to interpret the function of the firm, including the identification of moral or philosophical guidelines for its operation and management (Cragg, 2002). In this light, ST has an ethical dimension (Purnell and Freeman, 2012) because relationships with stakeholders reflect not only economics but also ethical and moral principles (Jones and Wicks, 1999). In other words, stakeholders should be considered the aim of the organisation rather than instruments to increase profitability.

This topic is logically connected with the concept and definition of an organisation's stakeholders. Freeman (1984, p. 46) broadly defined stakeholders (including shareholders) as "any group or individual who can affect or is affected by the achievement of corporation's purpose". Over time the term "stakeholders" has assumed a broader meaning to include individuals who affect or are affected by organisations but have no direct economic relationship to them (Steurer, 
2006). This includes local community members and inhabitants of the city or region in which the organisation is located, gradually extending out to all of humanity, the natural environment and the planet (Byrd, 2007; Zhao et al., 2011). ST did not originally include these aspects because it did not consider the external impacts of organisational activities. Thus, over the course of its evolution, ST has become intertwined with corporate social responsibility and sustainability (Balmer et al., 2007; Hörisch et al., 2014).

More recently, firms are facing the evolution of socio-economic systems and problems such as climate change, economic inequality and global ecosystem risks (such as the COVID-19 pandemic). These issues require new answers, exceeding the boundaries of ST. In this regard, the consideration of stakeholders as the sole aim of organisations risks leaving them without strategic direction and bound to a mere survival perspective. The shared value approach of Porter and Kramer (2011) may provide an answer to this question, even if it appears to focus more on merging economic and social issues into business strategies than on firms as holistic systems.

Therefore, rather than evolving further, ST needs to be reconceived in light of the new challenges faced by organisations. In other words, ST should complement the purpose view of the firm claiming, according to Mayer (Millstein et al., 2019, p. 15), that "the purpose of business is not to produce profits. The purpose of business is to produce profitable solutions to the problems of people and the planet". A firm is an autonomous institution identified by its purpose and its executives, stakeholders (including shareholders), management and corporate governance systems must be aligned to that purpose rather than to profit.

The fundamental tenet of ST is the value created for stakeholders, who are grouped into different categories. Initially, stakeholders were divided into primary stakeholders, the ones influencing the company (Clarkson, 1995), claimants (Kaler, 2002), legitimate (Freeman et al., 2012), towards whom the organisation has obligations or duties (Donaldson and Preston, 1995) and secondary stakeholders, those who affect or are affected by the organisation but do not have the power to influence management decisions (Dunham et al., 2006). However, over its evolution, ST has expanded the concept of stakeholders to include all of humanity and the planet (Freeman, 2017). However, it is difficult to calculate the value created for stakeholders and define to whom this value should be disclosed. Managerial ST addressed relations with and disclosure to primary stakeholders, given their power to influence the organisation. With respect to normative ST and the purpose of the organisation, all stakeholders are potentially interested in understanding the mission of the organisation and in verifying whether and how this mission is being accomplished, whilst organisations are interested in stakeholder legitimacy.

However, until now, the measurement, reporting and disclosure of created value for stakeholders have been underexplored and they deserve to be better investigated because they are necessary to concretely fulfil ST. Indeed, only by measuring, reporting and disclosing created value is it possible to verify the effective pursuit of an organisation's mission.

\subsection{When stakeholder theory intersects the international integrated reporting framework: past and future development}

The IIRF is a well-known tool for the non-financial disclosure of organisations. It aims to enable organisations to report and disclose their ability to create value in the medium and long term (Cheng et al., 2014; Dumay et al., 2016; De Villiers et al., 2020).

The IIRF is based on integrated thinking, a multi-capital management approach that enables organisations to disclose their purpose to the benefit of their key stakeholders' overtime (Guthrie et al., 2017; Feng et al., 2017; Al-Htaybat and von Alberti-Alhtaybat, 2018). The IIRF has adopted a multi-capital perspective assuming that the ability of an organisation to create 
MEDAR 30,3

value in the long term depends on its stock of six different capitals (financial, manufactured, intellectual, human, social/relational and natural) and is measured by the increase or decrease in these capitals through its business model and processes (Camilleri, 2018).

The IIRF is rooted in theories such as the resource-based view (Barnabè et al., 2019) or intellectual capital (Melloni, 2015; Garanina and Dumay, 2017); it is built on the idea that an organisation's success depends not only on its financial capital but also on a broader range of various financial and non-financial, tangible and intangible capitals (Coulson et al., 2015). IR is primarily aimed at the providers of financial capital (Flower, 2015), even if it can benefit all stakeholders interested in an organisation's ability to create value. The concept of created value refers to the value an organisation creates for itself, as well as (in a subordinate way) for external "others" (Barnabé, 2016; Barnabè et al., 2019). From this perspective, the IIRF seems aligned with ST (Rowbottom and Locke, 2016).

In the IIRF, stakeholders are defined as "others"; they include both main stakeholders and society at large. Key stakeholders are the legitimate individuals or groups that have needs or expectations to be satisfied by the organisation and are used to delimit the boundaries of IR (Mio and Fasan, 2013), with consideration of the risks, opportunities and outcomes attributable to or associated with well-defined stakeholders (IIRF, p. 19). Stakeholders are considered only if they have a significant impact on the ability of the organisation to create value. This notion of stakeholders recalls the traditional concept suggested by ST, meaning only primary stakeholders, whilst secondary stakeholders, including humanity and the environment, are excluded because they lack materiality (Fasan and Mio, 2017). Following this idea, IR only discloses the relationships an organisation creates and maintains with its key stakeholders and how and to what extent the organisation takes into consideration their legitimate expectations and needs (Vitolla et al., 2019a, 2019b).

From these perspectives, the IIRF appears outdated with respect to the evolution of ST and the purpose view of the organisation. Its weaknesses can be summarised as follows:

- The IIRF limits value creation to the value the organisation creates for itself and measures it by changes in six different capitals. This concept overcomes the idea of value creation as the change in financial capital but neglects the value that organisations create for stakeholders (Flower, 2015; Vitolla et al., 2019a, 2019b).

- Integrated reporting is only addressed to providers of financial capital, even if all stakeholders can benefit from it (Sukhari and De Villiers, 2019). IR beneficiaries should comprise all stakeholders, including primary stakeholders being informed about the value created for them and secondary stakeholders (including humanity and the environment) being informed about how the organisation contributes to solving global problems in following its purpose and implementing its mission.

- Finally, stakeholders are considered in an opportunistic manner (Farneti et al., 2019) and IR only discloses the relationships the organisation creates and maintains with them (Brown and Dillard, 2014; Mio and Fasan, 2013). However, stakeholders should be considered as actors participating in the pursuit of the organisation's mission and aims and be included in the organisation's business model and IR should disclose the value created by and for them.

Therefore, the IIRF could undergo some adjustments to enable the better disclosure of the role of all stakeholders in value creation. 


\section{Revisited integrated reporting framework}

The previous sections highlighted the main features of ST and the limitations of IIRF in disclosing the value created for stakeholders. To improve these limitations, adjustments to the IIRF are suggested, derived from a deductive process in which ST was matched with the weaknesses of the IIRF.

\subsection{First adjustment: the need to identify organisational stakeholders}

According to ST and the purpose view of firms, all organisations exist to meet the needs and expectations of stakeholders by creating value (Freeman and Ginena, 2015; Mayer, 2018). This reveals the first critical limitation of the IIRF, which assumes that value creation consists only in increases in the organisation's capitals and overlooks stakeholder satisfaction. Moreover, it does not include stakeholders in the business model, instead of relegating them to social and relational capital.

To overcome this limitation, an organisation's stakeholders must be recognised in the business model. Stakeholder recognition should follow a clear statement of the organisation's value proposition, including the firm's purpose and mission in terms of the needs and expectations to be met (Lanning and Michaels, 1988; Kaplan and Norton, 2004). According to Osterwalder et al. (2014), a value proposition enables the identification of those to whom a firm's offerings are directed - its customers and users. These are the main stakeholders because their needs and expectations are at the core of the organisation's mission. In this sense, they can be considered primary stakeholders, in contrast to the definitions prevailing in the ST literature. Furthermore, a value proposition enables an organisation to identify other stakeholders (including shareholders) important for business success whose expectations must be fulfiled to maintain their cooperation over time. These stakeholders may be considered secondary stakeholders, also in contrast to definitions in the ST literature. These stakeholders must be identified, engaged and managed to implement the value proposition.

It is worth noting that this distinction between primary and secondary stakeholders only underlines the different roles they play in the business model, but both of them are considered essential to the survival of the firm. In this way, humanity and the environment are excluded from the business model but not from IR. Humanity can be included in the social and relational capital in terms of the impacts engendered by an organisation when following its purpose and mission and the environment can similarly be included in Natural capital. The social and relational capital is still one of the six capitals including assets such as corporate image, reputation and affordability; it concurs with value creation as it fosters relationships and attraction of qualified resources, whilst stakeholders are specifically identified in the business model; the satisfying answer to their expectations contributes to increasing the social and relational capital.

Thus, the first suggested adjustment is:

A1. To highlight the organisation's stakeholders as components of the business model instead of leaving them hidden into social and relational capital and to classify them into primary and secondary stakeholders.

\subsection{Second adjustment: the need to focus on the real meaning and recipients of value creation}

The IIRF considers created value only in terms of increased capital, but value creation should consider an organisation's impact on sustainability and its ability to fulfil stakeholders' needs and expectations (Freeman and Ginena, 2015). To overcome this second 
MEDAR

30,3

limitation, it is useful to refer to the impact value chain model (IVCM) developed by scholars and institutions focussing on social enterprise value creation. This model focusses on how organisations affect people, communities and the natural environment through their production of both outputs, outcomes and social impact. In the IVCM, outputs are the measurable units of production yielded by the organisation, whilst outcomes are the benefits for stakeholder well-being (GECES Social, 2014; Hehemberger et al., 2015). Therefore, The IVCM also considers the benefits delivered to the stakeholders as value created by the organisation.

Reporting changes in both capital and stakeholder satisfaction is important because there must be a long-term equilibrium kept between and within them. The various capitals must be balanced and strengthened to implement the value proposition and ensure value creation for stakeholders (Rusconi, 2019). However, the measurement of these components in the reporting and disclosure of value creation is challenging. Capitals can be tangible or intangible and maybe measured objectively or subjectively. Similarly, stakeholder satisfaction is a complex and qualitative value that depends on tangible and intangible factors such as financial remuneration, just and fair treatment, the benefits of being affiliated with the organisation and possible alternative treatment by other firms (Harrison and Wicks, 2013). Therefore, an appropriate and firm-specific mix of key performance indicators (KPIs) needs to be developed and possibly integrated by some narrative able to improve the information quality: KPIs validate the narrative by objective references and narrative provides KPIs with a framework useful to better appreciate them.

Thus, a second adjustment to IIRF is suggested to highlight two different but interconnected components of created value:

A2. Report and disclose both the changes in capitals and the outcomes produced in fulfiling stakeholder needs and expectations.

\subsection{Third adjustment: Capacity and means to create value for stakeholders}

ST suggests an innovative vision of firms in which the expectations of all categories of stakeholders are considered. In contrast, the IIRF is directed at providers of financial capital and neglects the capacity of organisations to satisfy stakeholder needs. For this reason, the IIRF does not analyse the activities conducted by the organisation to implement its value proposition nor does it classify these activities as drivers of value creation. In other words, it fails to reveal how capitals affect outputs and outcomes, making the organisation's processes a "black box". This is another limitation of the IIRF that requires specific adjustments.

According to Osterwalder et al. (2014), business processes can be identified starting from the value proposition. To classify business processes, we adopted a modified version of Porter's value chain (Donna, 1992), which includes the following three processes:

- Direct processes refer to the production and delivery of valuable goods and services.

- Indirect processes refer to the resources and services that support direct processes (e.g. human resource management, quality management systems, logistics systems, product and process innovation).

- Supporting processes refer to the acquisition and development of organisational resources (e.g. manufacturing and logistic infrastructure, research and development and recruitment). 
An analysis of business processes is important to explain how they are connected to capitals, stakeholders and value creation, shedding light on the drivers of value and highlighting relevant interdependencies amongst the components of the business model. Value for stakeholders, in particular, arises from the business processes fed by the capitals that are continuously used and (re)produced by firms. An organisation produces capital as an effect of its own processes; for example, the production of financial resources from selling goods and services, the development of skills and knowledge through personnel training, increasing experience through operations, improving technology through research and development and working with partners and improving the environment through the adoption of green processes and products. Conversely, an organisation attracts capital and stakeholders as a consequence of its ability to reward them; for example, it attracts financial resources from shareholders, human resources through recruitment, knowledge from partners and suppliers and technology through licensing (Farneti et al., 2019).

A value proposition that is consistent with an organisation's mission and purpose and safeguards social and natural capitals involves the use of resources and processes with positive economic, social and environmental impacts, improving natural, social and relational capitals and corporate image and reputation and making the organisation more attractive to stakeholders.

Providing a clear understanding of how business processes may connect capitals and stakeholders to create value and adjusted IIRF can foster awareness of the organisation's business model, enable organisational learning and integrated thinking and support better governance and management decisions. To overcome the limitations in the IIRF, a third adjustment is suggested:

A3. Disclose direct, indirect and supporting business processes to highlight how the organisation creates value for each category of stakeholders.

\section{Testing and validating the modified international integrated reporting framework: the Gigi Ghirotti Association}

In 2018, GGA management contacted the Department of Economics and Business Studies at the University of Genoa because it was unsatisfied with the ability of its social reporting to effectively communicate its created and distributed value to stakeholders. According to the GGA president:

Even if GGA has been issuing a social report from 2009, we think that this document is not effective in disclosing the value the association creates for both the patients and the community. However, we are not able to clearly explain the reasons for our dissatisfaction nor how to improve the social report.

To support GGA in improving its disclosure, the research team conducted semi-structured interviews to understand the weaknesses of the previous social report and design an improved instrument appropriate for GGA needs. From these interviews, the following needs arose:

- Although GGA primarily offers services to specific patients, it also plays a pivotal role in serving indirect beneficiaries and the wider community. GGA needs to identify and classify its broad range of stakeholders and communicate its role and mission to all stakeholder categories.

- GGA currently issues two separate documents - a financial report and a social report. It is unable to measure and report their joint performance nor link them with its mission. 
MEDAR

30,3

- Although the GGA is aware of its processes, it does not understand how they create and deliver value to all stakeholders, thus, is unable to communicate and report them.

According to the CFO, "We would like to inform all the people getting in touch with us about what we do, why we do it and how and how well we pursue our purpose".

Some of the needs expressed by GGA managers could have easily been met by implementing the IIRF, which would have enabled them to:

- adopt a multi capital vision of the organisation that considers both financial and non-financial capitals, including relational, human and intellectual capitals, which are essential for the specific activities of GGA;

- adopt integrated thinking, overcoming the limitations of issuing separate reports on the financial and non-financial performance of the organisation.

However, given the weaknesses discussed above, the IIRF could not have addressed all of the GGA's reporting needs. For example, the IIRF:

- does not require an explicit statement of the organisation's purpose and value proposition; in fact, the "Organisational overview and external environment" content element focusses mainly on the external context and environmental changes rather than on the role the organisation intends to play; if drawn up, it should include a clear statement of the business purpose or raison d'etre;

- does not include stakeholders as part of the business model but considers them components of social and relational capital;

- lacks an explicit link between business processes and stakeholders, thus, fails to disclose how the organisation creates value for them.

The disclosure needs of the GGA and the weaknesses of the IIRF provided an opportunity to test and validate the modified IIRF. During the action research, the research team in cooperation with the GGA delegates implemented the modified IIRF, collecting empirical evidence about the validity of the suggested framework.

\subsection{The need to identify and communicate with stakeholders}

GGA must communicate with a broad range of stakeholders. This addresses the first IIRF limitation, which considers stakeholders as "others" and in an opportunistic way. Moreover, stakeholders are not included in the business model but hidden in social and relational capital. To overcome this limitation, we conducted an empirical activity to answer the following questions: What kind of value does the organisation create? For whom is this value created? To answer these questions, the mission and purpose of the organisation were first examined, showing that the main aims of the organisation were to:

- provide patients and their families with high-quality services;

- play a high-level role in the local context, fulfiling the needs and expectations of the community.

The identification of these purposes enabled the clarification of two different groups of stakeholders:

- primary stakeholders: those directly benefiting from GGA services (patients and their families); 
- secondary stakeholders: those receiving indirect benefits from the organisation, including volunteers and donors, who receive satisfaction from their philanthropic activities; employees and professionals, who are rewarded by their work; and local health services, which expect a high-quality health-care service.

The expectations of the primary stakeholders are at the core of the GGA's mission. Secondary stakeholders provide the organisation with resources and legitimacy that are critical for its survival and their satisfaction is crucial to maintain their cooperation over

Value creation disclosure time:

Therefore, we implemented the first IIRF adjustment by extracting stakeholders from social and relational capital, including them in the business model and classifying them as primary and secondary stakeholders. In this way, stakeholders were clearly linked with the organisation's value proposition. The $\mathrm{COO}$ commented, "This classification permits GGA to clearly communicate that patients are not the only recipients of our value proposition, as a broader set of actors are involved in the value creation process, including the whole local community".

\subsection{Demonstrating delivered value}

In its report, GGA must clearly demonstrate the value created and delivered to all stakeholders. A limitation of the IIRF is that it only considers the value the organisation creates for itself, measured by variations in the six capitals and neglects outcomes with respect to stakeholder satisfaction. To overcome this limitation, the organisation's business processes were analysed on two levels: their effect on the six capitals and their contributions to the needs of primary and secondary stakeholders.

The first level of analysis identified the most important GGA capitals, which affect the ability of the organisation to create value in the long term. These capitals were:

- human capital, especially staff and volunteers, including their duties and competencies;

- organisational capital, comprising operating procedures and quality management systems;

- social and relational capital is reflected in the organisation's image and reputation.

The second level of analysis pertained to organisational outcomes in terms of stakeholder satisfaction. Primary stakeholder satisfaction was based on surveys of service quality. Secondary stakeholder satisfaction was based on the following indicators:

- the number and continuity of volunteers as a proxy of their satisfaction with working at GGA;

- the level and continuity of grants as a proxy of GGA's image and reputation;

- staff conflicts as a proxy of organisational climate;

- disputes with health service agencies as a proxy of institutional compliance.

According to the president of the GGA, "Our work is well done and our mission is reached if all the stakeholders are satisfied and all of them legitimise our role in the community".

The second adjustment is realised reporting not only the increase in capitals, reflecting the value the organisation creates for itself but also KPIs to measure the value it creates for stakeholders. 
MEDAR

30,3

752

\subsection{Connecting value creation, stakeholders and business processes}

The GGA needed a better understanding of how its business processes create value for each category of stakeholders by connecting its six capitals - especially the crucial ones - to its outcomes. Another limitation of the IIRF is that it considers the business model a "black box" and fails to analyse the organisation's activities to transform the capital into outputs and outcomes.

To overcome this limitation, a third adjustment was implemented in which the GGA value chain was defined as comprising the following three sets of activities:

- direct processes: the assistance delivered to patients at home and in hospices;

- indirect processes: human resource and quality system management;

- supporting processes: development, innovation, communication and fundraising.

The report was then drafted to classify business processes as direct, indirect and supporting processes and highlight the relevant capitals, processes, stakeholders and values, as well as the strategic interdependencies between these elements. The CFO commented, "This integrated reporting permits to us to foster awareness of our business model, making clear the value creation process and the role the intangible capitals play in it". According to the COO, "Thanks to the IR and the clarification of our business processes, we have a sound basis to enable organisational learning and integrated thinking, as well as proactive management practices".

This implementation activity enabled us to validate the adjusted IIRF, emerging from both the quality of the report and the satisfaction of the GGA managers. According to the CFO, "The IR can deliver a comprehensive narrative about our purpose, to link the purpose with the people receiving benefits in a different way and to measure intangible performance through ad-hoc KPIs". Similarly, the GGA president commented, "This document will be crucial to communicate with both patients and other stakeholders, especially the ones by which we expect legitimation, consensus and [...] funding!". The $\mathrm{COO}$ further remarked:

[The] IR demonstrates to be useful not only as a disclosure instrument but also as a management tool as we are now more aware of who are our stakeholders and which processes deliver value to each of them; therefore, we can also be more effective in managing these processes for value delivered.

Table 2 summarises the findings of the research, linking the ST assumptions, IIRF weaknesses and the suggested adjustments. Column 4 describes the empirical implications and possible generalisations arising from the implementation of the adjusted IIRF in the GGA. The following section discusses these findings further.

Figure 1 shows how the adjustments modify the original IIRF. Stakeholders are no longer hidden in the social and relational capital but are part of the business model; the value creation is reported not only as increasing (or decreasing) of the six capitals but also as stakeholders' satisfaction; and finally, the satisfaction of the stakeholders' expectations is casually linked with the direct, indirect and supporting business processes. This suggested new setting improves the integrated reporting further, feeding the integrated thinking.

\section{Findings and discussion}

In suggesting that the role of a firm is not only to create value for shareholders but also to satisfy the expectations of a broad range of stakeholders, ST requires organisations to find a different way of measuring, disclosing and communicating created value. The IIRF appears to offer this because it considers value creation to be more than simply an increase in financial capital. However, a deeper comparison of ST and the IIRF and an analysis of the 


\begin{tabular}{l}
\hline ST assumption \\
\hline Stakeholders are \\
classified as \\
primary and \\
secondary and \\
broadly defined as \\
groups or \\
individuals that \\
affect and are \\
affected by \\
corporations
\end{tabular}

IIRF weakness
Stakeholders are
considered "others" and in
an opportunistic way

IIRF adjustments

Empirical implications

Identify the organisation's stakeholders

Separate stakeholders from social and relational capital Classify stakeholders into key and other stakeholders

Identifying, separating disclosure and classifying stakeholders improves the quality of disclosure and shows the organisation's aims. The case study showed that extracting stakeholders from social and relational capital and classifying them with respect to their role in the business model enables the organisation to improve its value proposition and communication

Value creation is not limited to the value created for shareholders
Value creation is limited to the value an organisation creates for itself
Consider created value as not only an increase in the six capitals but also an increase in the satisfaction of stakeholders
Including the satisfaction of stakeholders in value creation can help in designing a better value proposition and verifying the function of the organisation with respect to its stakeholders. The case study showed that with the adjusted IIRF, it is easier to identify appropriate KPIs to measure value creation for stakeholders Disclosing all business processes highlights how all stakeholders expectations are met. The case study demonstrated that the adjusted IIRF is not only an effective disclosure tool but also an effective management tool because it links business processes to performance
Table 2.

Theoretical and empirical

implications of the
An innovative meets the expectations of all stakeholders expectations of all stakeholders value for each category of stakeholders 
Figure 1.

The adjusted IIRF

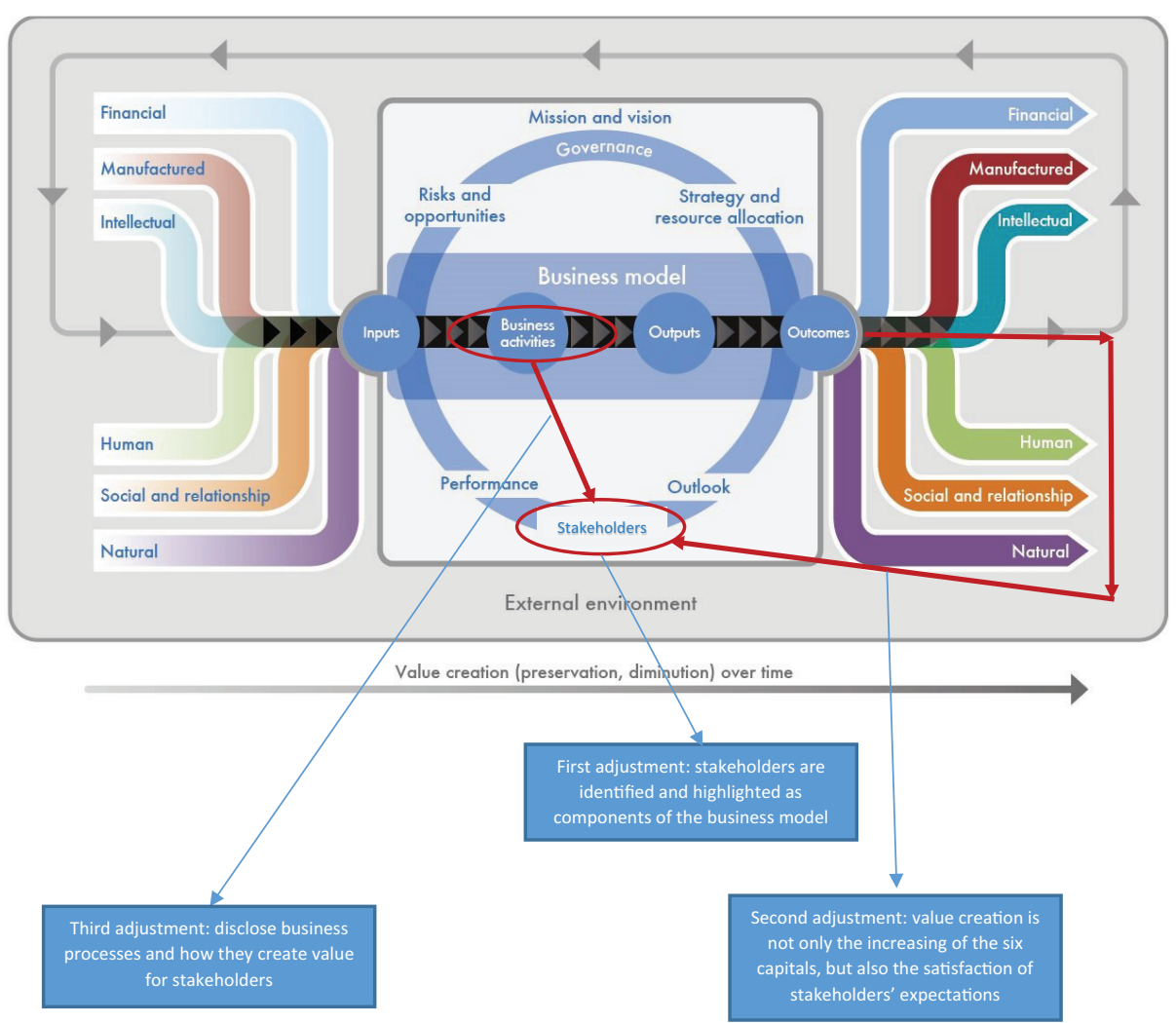

extensive literature on these topics revealed the limitations of the IIRF that prevent its reporting and disclosure capacity in the light of ST.

ST is based on the fundamental role of stakeholders in contributing to the success of a company. Beginning from a managerial point of view, it is gradually evolving to incorporate ethics and the purpose view of the firm. Whilst primary and secondary stakeholders actively contribute to a firm's mission and value proposition, other stakeholders are satisfied that the firm is making positive impacts on social and natural capital.

Three pivotal aspects must be considered: overcoming the primacy of shareholders, the analysis and classification of stakeholders and the need to understand how organisation can satisfy stakeholders' expectations through its processes. The IIRF is lacking in all of these aspects: it considers the providers of financial capital the primary recipients of IR, allocates stakeholders to social and relational capital without any analysis or classification and fails to disclose business processes with respect to how an organisation creates value for its stakeholders.

Although these limitations have been highlighted previously, until now, there have been no practical attempts to overcome these weaknesses. Several researchers have also investigated how ST may affect IR, including the content of disclosed information, stakeholder pressure with respect to reporting quality and attention paid to social and 
environmental issues. However, no studies have investigated whether the IIRF satisfies ST with respect to reporting and disclosure.

The aim of the present study was to overcome this final hurdle by reviewing the studies on the relationship between ST and IIRF and making modifications to the IIRF to implement ST. Three adjustments were applied to the IIRF to improve its ability to incorporate ST as a theoretical foundation. The three adjustments were made following a deductive process in which the weaknesses of the IIRF were matched with the assumptions of ST. The following three adjustments were made in an attempt to solve the issues revealed by the literature review: the removal of stakeholders from the social and relational capital to overcome the shallow and opportunistic view of stakeholders conceived by the IIRF; the addition of KPIs to measure the value created for stakeholders and overcome the outdated consideration of providers of financial capital as the primary addressers of value creation and the disclosure of business processes to clarify how organisations can satisfy stakeholder expectations.

The modified IIRF was conceived as a ready-to-use tool. By applying it to a business case, it was validated with respect to whether and how it could help achieve better and more stakeholder-oriented reporting. The findings enabled us to validate the use of the tool not only for reporting but also for the self-assessment of organisations with respect to embedding ST.

Firstly, individuating stakeholders is a way of improving the quality of reporting. Extracting stakeholders from social and relational capital gives them visibility and legitimacy whilst classifying them enables organisations to better address both their value proposition and communications.

Secondly, defining value creation not only in terms of increased capital but also increased stakeholder satisfaction can improve the design of the value proposition and verify the function of the organisation with respect to its stakeholders. The modified IIRF facilitated the identification of appropriate KPIs by which to measure value creation for stakeholders.

Thirdly, disclosing the business processes enabled the organisation to highlight its pursuit of stakeholder satisfaction. The modified IIRF links each category of stakeholders with specific KPIs through the organisation's business processes. This is in contrast to the traditional IIRF, where stakeholders are hidden in social and relational capital and business processes are hidden in the "black box" of the business model. The IIRF conceives the business model as an empty box, without specifying which business processes do what and for whom. The case study demonstrated that the modified IIRF is not only an effective disclosure instrument but also an effective managerial tool because it links business processes to performance and supports integrated thinking and strategic decisions.

\section{Conclusion}

The modified IIRF proposed in this paper is a promising reporting and disclosure tool for stakeholder- and purpose-oriented organisations aimed at better focussing the role of stakeholders in value creation.

This work fits with a wider stream, regarding the future of the international integrated reporting council (IIRC)/IIRF and its convergence towards sustainability reporting. The announcement of the merging of IIRC, which is currently focussed on reporting value creation in the medium/long term and sustainability accounting standard board, which is committed to standards for monitoring sustainability into the Value Reporting Foundation, certainly represents a step forward in the direction of a unified sustainability reporting model. Moreover,
Value creation disclosure

755 
MEDAR

30,3

it is worth remembering that the European Union is launching a new directive on sustainability reporting intended to replace the old one on non-financial information.

All that is working towards, like this paper, a greater focus on sustainability and stakeholders, motivated by the following aspects:

- the belief that the future of an organisation depends on its ability to create value by carrying out an economically, socially and ethically useful function, starting with a clear identification of its purpose and value proposition;

- that implementing purpose and value proposition involves satisfying the expectations of shareholders and stakeholders bringing the organisation resources, skills and legitimacy, but to do so, the organisation has to generate resources enough to feed these responses; in other words, there has to be a balance between the value shareholders and stakeholders create and receive;

- that there is, however, a difference between shareholders and stakeholders directly involved in value creation and distribution and the external entities that benefit from or are damaged by the economic, social and environmental impacts engendered by an organisation.

Based on these considerations, it should be emphasised that the revised IIRF represents an updated reporting and disclosure tool for the value created in a broad sense by an organisation. On the one hand, it can encompass financial, manufactured, intellectual, human, social and relational and natural capital and on the other, the answers provided both to shareholders and stakeholders directly involved in value creation and external entities the organisation impacts through its activities. In this way, the IIRF can give visibility to all value created and the value creation process, including sustainability matters as external impacts; it allows the integrated thinking processes to be incorporated accordingly. Therefore, the modified IIRF can provide better information not only to capital providers but also to all stakeholders (including shareholders) interested in the sustainable success of the business model.

Despite the suggested modifications being based on well-founded theories and concepts, the modified framework has some theoretical problems that need suitable solutions. In particular, some capitals are intangible, whilst stakeholder satisfaction is linked to complex qualitative values that depend on both material and immaterial factors. In both cases, new metrics should be developed and tested for their ability to report and disclose created value.

Moreover, the modified IIRF was implemented only in one case and further implementations are needed to comprehensively identify its strengths and weaknesses, both in for-profit and non-profit organisations. In for-profit organisations, the organisation's purpose, as well as its value proposition as a link with business activities, must be clearly highlighted. A dynamic balance must be found between shareholders' and stakeholders' expectations. In non-profit organisations, primary stakeholders and their expectations are usually implicit in the institutional nature of the organisation. Further studies should be conducted to overcome the limitations of the present work by applying the modified framework to a large sample of organisations from both the private and non-profit sectors.

\section{References}

Adams, C.A. (2015), "The international integrated reporting council: a call to action", Critical Perspectives on Accounting, Vol. 27, pp. 23-28.

Adams, S. and Simnett, R. (2011), "Integrated reporting: an opportunity for Australia's not-for-profit sector", Australian Accounting Review, Vol. 21 No. 3, pp. 292-301. 
Al-Htaybat, K. and von Alberti-Alhtaybat, L. (2018), "Integrated thinking leading to integrated reporting: case study insights from a global player", Accounting, Auditing and Accountability Journal, Vol. 31 No. 5, pp. 1435-1460.

Asher, C.C., Mahoney, J.M. and Mahoney, J.T. (2005), "Towards a property rights foundation for a stakeholder theory of the firm", Journal of Management and Governance, Vol. 9 No. 1, pp. 5-32.

Balmer, J.M., Fukukawa, K. and Gray, E.R. (2007), "The nature and management of ethical corporate identity: a commentary on corporate identity, corporate social responsibility and ethics", Journal of Business Ethics, Vol. 76 No. 1, pp. 7-15.

Barnabé, F. (2016), "Representing' value creation: a combined approach of system dynamics and integrated reporting for the airline sector", International Journal of Applied Systemic Studies, Vol. 6 No. 3, pp. 202-222.

Barnabè, F., Giorgino, M.C. and Kunc, M. (2019), "Visualizing and managing value creation through integrated reporting practices: a dynamic resource-based perspective", Journal of Management and Governance, Vol. 23 No. 2, pp. 537-575.

Barney, J.B. (2018), "Why resource-based theory's model of profit appropriation must incorporate a stakeholder perspective”, Strategic Management Journal, Vol. 39 No. 13, pp. 3305-3325.

Biondi, L., Dumay, J. and Monciardini, D. (2020), "Using the international integrated reporting framework to comply with EU directive 2014/95/EU: can we afford another reporting façade?", Meditari Accountancy Research, Vol. 28 No. 5, pp. 889-914.

Brown, J. and Dillard, J. (2014), “Integrated reporting: on the need for broadening out and opening up", Accounting, Auditing and Accountability Journal, Vol. 27 No. 7, pp. 1120-1156.

Burns, D. (2007), Systemic Action Research: A Strategy for Whole System Change, Policy Press, Bristol.

Byrd, E.T. (2007), "Stakeholders in sustainable tourism development and their roles: applying stakeholder theory to sustainable tourism development", Tourism Review, Vol. 62 No. 2, pp. 6-13.

Camilleri, M.A. (2018), "Theoretical insights on integrated reporting: the inclusion of Non-Financial capitals in corporate disclosures", Corporate Communications: An International Journal, Vol. 23 No. 4, pp. 567-581.

Carr, W. and Kemmis, S. (1986), Becoming Critical: education Knowledge and Action Research, Falmer Press. Philadelphia.

Chandra, Y. and Shang, L. (2019), "Inductive coding”, in Chandra Y. and Shang L. (Eds), Qualitative Research Using R: A Systematic Approach, Springer, Singapore.

Cheng, M., Green, W., Conradie, P., Konishi, N. and Romi, A. (2014), "The international integrated reporting framework: key issues and future research opportunities", Journal of International Financial Management and Accounting, Vol. 25 No. 1, pp. 90-119.

Clarkson, M.E. (1995), "A stakeholder framework for analyzing and evaluating corporate social performance", Academy of Management Review, Vol. 20 No. 1, pp. 92-117.

Coulson, A.B., Adams, C.A., Nugent, M.N. and Haynes, K. (2015), "Exploring metaphors of capitals and the framing of multiple capitals: challenges and opportunities for. Sustainability accounting", Management and Policy Journal, Vol. 6 No. 3, pp. 290-314.

Cragg, W. (2002), "Business ethics and stakeholder theory", Business Ethics Quarterly, Vol. 1, pp. 113-142.

Dameri, R.P. and Ferrando, P.M. (2020), "Implementing integrated reporting to disclose intellectual Capital in health organisations: a case study", Journal of Intellectual Capital, Vol. 22 No. 2.

De Villiers, C., Rinaldi, L. and Unerman, J. (2014), "Integrated reporting: insights, gaps and an agenda for future research", Accounting, Auditing and Accountability Journal, Vol. 27 No. 7, pp. 1042-1067. 
MEDAR

30,3

De Villiers, C., Venter, E.R. and Hsiao, P.C.K. (2017), "Integrated reporting: background, measurement issues, approaches and an agenda for future research", Accounting and Finance, Vol. 57 No. 4, pp. 937-959.

De Villiers, C., Hsiao, P.C., K. and Maroun, W. (2020), The Routledge Handbook of Integrated Reporting, Routledge, London.

Dodd, C.H. (1932), "The framemork of the gospel narrative”, The Expository Times, Vol. 43 No. 9, pp. 396-400.

Donaldson, T. and Preston, L.E. (1995), "The stakeholder theory of the corporation: Concepts, evidence and implication". Academy of Management Review, Vol. 20.

Donna, G. (1992), L’impresa Competitiva, Un approccio sistemico. Giuffré, Milano.

Dumay, J., Bernardi, C., Guthrie, J. and Demartini, P. (2016), "Integrated reporting: a structured literature review", Accounting Forum, Vol. 40 No. 3, pp. 166-185.

Dunham, L., Freeman, R.E. and Liedtka, J. (2006), "Enhancing stakeholder practice: a particularized exploration of community", Business Ethics Quarterly, Vol. 16 No. 1, pp. $23-42$.

Eisenhardt, K.M. (1989), "Building theories from case study research", Academy of Management Review, Vol. 14 No. 4, pp. 532-550.

Farneti, F., Casonato, F., Montecalvo, M. and De Villiers, C. (2019), "The influence of integrated reporting and stakeholder information needs on the disclosure of social information in a stateowned enterprise", Meditari Accountancy Research, Vol. 27 No. 4, pp. 556-579.

Fasan, M. and Mio, C. (2017), "Fostering stakeholder engagement: the role of materiality disclosure in integrated reporting", Business Strategy and the Environment, Vol. 26 No. 3, pp. 288-305.

Feng, T., Cummings, L. and Tweedie, D. (2017), "Exploring integrated thinking in integrated reporting-an exploratory study in Australia”, Journal of Intellectual Capital, Vol. 18 No. 2, pp. 330-353.

Fink, A. (2005), Conducting Research Literature Reviews: From the Internet to Paper, 2nd ed., Sage Publications. Thousand Oaks, CA.

Flower, J. (2015), "The international integrated reporting council: a story of failure", Critical Perspectives on Accounting, Vol. 27, pp. 1-17.

Freeman, R.E. (1984), Strategic Management: A Stakeholder Approach, Pitman. Marshfield, MA.

Freeman, R.E., Rusconi, G., Signori, S. and Strudler, A. (2012), "Stakeholder theory (ies): ethical ideas and managerial action", Journal of Business Ethics, Vol. 109 No. 1, p. 1.

Freeman, R.E. and Ginena, K. (2015), "Rethinking the purpose of the corporation: challenges from stakeholder theory", Notizie di Politeia, Vol. 31 No. 117, pp. 9-18.

Freeman, R.E. (2017), "Five challenges to stakeholder theory: a report on research in progress", In Stakeholder Management, Emerald Publishing Limited.

Frias-Aceituno, J.V., Rodríguez-Ariza, L. and García-Sánchez, I.M. (2013), "Is integrated reporting determined by a country's legal system? An exploratory study", Journal of Cleaner Production, Vol. 44, pp. 45-55.

Friedman, A.L. and Miles, S. (2006), Stakeholders: Theory and Practice, Oxford University Press, Oxford.

Garanina, T. and Dumay, J. (2017), "Forward-looking intellectual Capital disclosure in IPOs”, Journal of Intellectual Capital, Vol. 18 No. 1, pp. 128-148.

García-Sánchez, I.M. and Noguera-Gámez, L. (2017), "Integrated reporting and stakeholder engagement: the effect on information asymmetry", Corporate Social Responsibility and Environmental Management, Vol. 24 No. 5, pp. 395-413.

GECES Social (2014), “Impact measurement SubGroup”, Report adopted, available at: www.febea.org 
Guthrie, J., Manes-Rossi, F. and Orelli, R.L. (2017), "Integrated reporting and integrated thinking in italian public sector organisations", Meditari Accountancy Research, Vol. 25 No. 4, pp. 553-573.

Harrison, J.S. and Wicks, A.C. (2013), "Stakeholder theory, value, and firm performance", Business Ethics Quarterly, Vol. 23 No. 1, pp. 97-124.

Harrison, J.S., Phillips, R.A. and Freeman, R.E. (2020), "On the 2019 business roundtable "statement on the purpose of a corporation”, Journal of Management, Vol. 46 No. 7, pp. 1223-1237.

Hehemberger, L. Harling, A.M. and Sholten, P. (2015), "A practical guide to measuring and managing impact”, EVPA, available at: https:/evpa.eu.com/

Hörisch, J., Freeman, R.E. and Schaltegger, S. (2014), "Applying stakeholder theory in sustainability management: links, similarities, dissimilarities, and a conceptual framework", Organization and Environment, Vol. 27 No. 4, pp. 328-346.

Hsieh, H.F. and Shannon, S.E. (2005), "Three approaches to qualitative content analysis”, Qualitative Health Research, Vol. 15 No. 9, pp. 1277-1288.

International Integrated Reporting Council (IIRC) (2013), "The international integrated reporting framework", available at: www.theiirc.org

Janssens, M., Brett, J.M. and Smith, F.J. (1995), "Confirmatory cross-cultural research: testing the viability of a corporation-wide safety policy", Academy of Management Journal, Vol. 38 No. 2, pp. 364-382.

Jensen, M.C. (2001), "Value maximization, stakeholder theory, and the corporate objective function", Journal of Applied Corporate Finance, Vol. 14 No. 3, pp. 8-21.

Jones, T.M. and Wicks, A.C. (1999), "Convergent stakeholder theory”, Academy of Management Review, Vol. 24 No. 2, pp. 206-221.

Kaler, J. (2002), "Morality and strategy in stakeholder identification", Journal of Business Ethics, Vol. 39 Nos 1/2, pp. 91-100.

Kaplan, R.S. and Norton, D.P. (2004), Strategy Maps: converting Intangible Assets into Tangible Outcomes, Harvard Business School Press, Boston, p. 10.

Kemmis, S., McTaggart, R. and Nixon, R. (2013), The Action Research Planner: Doing Critical Participatory Action Research, Springer Science and Business Media. New York, NY.

Lanning, M.J. and Michaels, E.G. (1988), “A business is a value delivery system”, McKinsey Staff Paper, Vol. 41, No. July.

Mayer, C. (2018), Prosperity. Better Business Makes the Greater Good, Oxford University Press, Oxford.

Melloni, G. (2015), "Intellectual capital disclosure in integrated reporting: an impression management analysis", Journal of Intellectual Capital, Vol. 16 No. 3, pp. 661-680.

Millstein, I., Gordon, J., Gilson, R., Mayer, C., Bresnahan, K. and Lipton, M. (2019), "Session I: corporate purpose and governance", Journal of Applied Corporate Finance, Vol. 31 No. 3, pp. 10-25.

Mio, C. and Fasan, M. (2013), “The case of ENEL”, in Busco, C., Frigo, M.L., Riccaboni, A., Quattrone, P. (Eds), Integrated Reporting. Concepts and Cases That Redefine Corporate Accountability, Springer International Publishing Switzerland, 225-236.

Osterwalder, A., Pigneur, Y., Bernarda, G. and Smith, A. (2014), Value Proposition Design: How to Create Products and Services Customers Want, New York, NY John Wiley and Sons.

Phillips, R., Freeman, R.E. and Wicks, A.C. (2003), "What stakeholder theory is not", Business Ethics Quarterly, Vol. 13 No. 4, pp. 479-502.

Phillips, R.A. and Freeman, R.E. (2010), Stakeholders, Edward Elgar Publishing.

Pitelis, C.N. and Wahl, M.W. (1998), "Edith penrose: Pioneer of stakeholder theory", Long Range Planning, Vol. 31 No. 2, pp. 252-261. 
MEDAR

30,3

Porter, M.E. and Kramer, M.R. (2011), “Creating shared value”, Harvard Business Review, Vol. 89 Nos. 1/2.

Purnell, L.S. and Freeman, R.E. (2012), "Stakeholder theory, fact/value dichotomy, and the normative core: how wall street stops the ethics conversation", Journal of Business Ethics, Vol. 109 No. 1, pp. 109-116.

Rensburg, R. and Botha, E. (2014), "Is integrated reporting the silver bullet of financial communication? A stakeholder perspective from South Africa”, Public Relations Review, Vol. 40 No. 2, pp. 144-152.

Rowbottom, N. and Locke, J. (2016), "The emergence of <IR>”, Accounting and Business Research, Vol. 46 No. 1, pp. 83-115.

Rowley, J. and Slack, F. (2004), "Conducting a literature review", Management Research News, Vol. 27 No. 6, pp. 31-39.

Rusconi, G. (2019), "Ethical firm system and stakeholder management theories: a possible convergence", European Management Review, Vol. 16 No. 1, pp. 147-166.

Samy, M. (2015), "Factors affecting the diffusion of integrated reporting-a UK FTSE 100 perspective", Sustainability Accounting, Management and Policy Journal, Vol. 6 No. 2, pp. 190-223.

Smith, H.J. (2003), "The shareholders vs. stakeholders debate”, MIT Sloan Management Review, Vol. 44 No. 4, pp. 85-90.

Steurer, R. (2006), "Mapping stakeholder theory anew: from the 'stakeholder theory of the firm'to three perspectives on business-society relations", Business Strategy and the Environment, Vol. 15 No. 1, pp. 55-69.

Stewart, R.F., Allen, J.K. and Cavender, J.M. (1963), “The strategic plan - LRPS report no. 168”, Long Range Planning Service, Stanford Research Institute, Menlo Park.

Sukhari, A. and De Villiers, C. (2019), "The influence of integrated reporting on business model and strategy disclosures", Australian Accounting Review, Vol. 29 No. 4, pp. 708-725.

Vitolla, F., Raimo, N. and Rubino, M. (2019a), "Appreciations, criticisms, determinants, and effects of integrated reporting: a systematic literature review", Corporate Social Responsibility and Environmental Management, Vol. 26 No. 2, pp. 518-528.

Vitolla, F., Raimo, N., Rubino, M. and Garzoni, A. (2019b), "The impact of national culture on integrated reporting quality. A stakeholder theory approach", Business Strategy and the Environment, Vol. 28 No. 8, pp. 1558-1571.

Yin, R.K. (1994), Case Study Research: design and Methods, 2nd ed. Sage. Newbury Park, CA.

Zambon, S., Marasca, S. and Chiucchi, M.S. (2019), "Special issue on the role of intellectual capital and integrated reporting in management and governance: a performative perspective", Journal of Management and Governance, Vol. 23 No. 2, pp. 291-297.

Zhao, J., Wu, M., Qian, G. and L., F. (2011), "An empirical research on the driving mechanism of corporation environmental performance based on stakeholder theory", China Environmental Science, Vol. 31 No. 11, pp. 1931-1936.

\section{Further reading}

Abhayawansa, S., Guthrie, J. and Bernardi, C. (2019), "Intellectual capital accounting in the age of integrated reporting: a commentary”, Journal of Intellectual Capital, Vol. 20 No. 1.

Laplume, A.O., Sonpar, K. and Litz, R.A. (2008), "Stakeholder theory: reviewing a theory that moves us”, Journal of Management, Vol. 34 No. 6, pp. 1152-1189.

\section{About the authors}

Renata Paola Dameri is an Associate Professor in Accounting at the University of Genoa, Department of Economics and Business Studies. Her research interests regard intellectual capital, not-for-profit organisations, non-financial disclosure, management information systems, smart city and smart city 
performance measurement, innovation, entrepreneurship and entrepreneurial university, management and entrepreneurship in the creative and cultural sector. She has published in Journal of Intellectual capital, IMA Journal of Managerial Mathematics, Journal of Information Systems, Knowledge Management Research and Practices, Technological Forecasting and Social Changes and Social Science Computer Review. Renata Paola Dameri is the corresponding author and can be contacted at:dameri@economia.unige.it

Pier Maria Ferrando is a Professor in Business Administration at the University of Genoa, Department of Economics and Business Studies and former Dean of the same Department. His research interests regard intellectual capital, value creation, business performance, non-profit organisations, non-financial disclosure, entrepreneurship and entrepreneurial university, innovative start-ups. He is the Editor in chief of the online scientific journal impresaprogetto - Electronic Journal of Management.

For instructions on how to order reprints of this article, please visit our website: www.emeraldgrouppublishing.com/licensing/reprints.htm Or contact us for further details: permissions@emeraldinsight.com 